\title{
Membangun keadaban digital warganet Indonesia dalam perspektif kewarganegaraan digital
}

\author{
Erwin Susanto, Dasim Budimansyah
}

Universitas Pendidikan Indonesia, Bandung, Indonesia

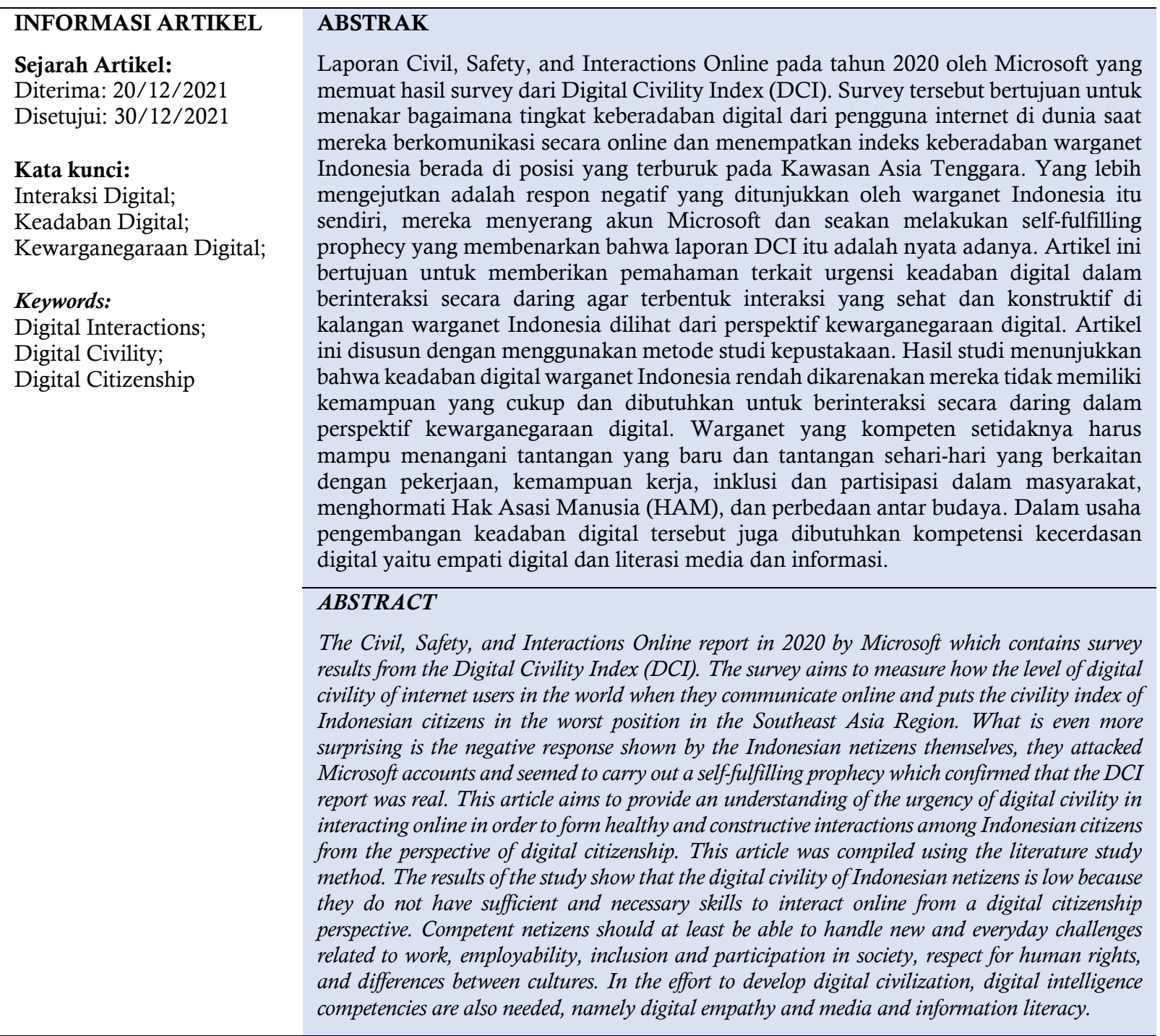

\section{Pendahuluan}

Perkembangan teknologi, informasi, dan komunikasi dewasa ini berkembang sangat cepat. Sebagai dampak yang terjadi akibat perkembangan teknologi, informasi dan komunikasi tersebut adalah meningkatnya jumlah pengguna internet di Indonesia. Survei Asosiasi Penyelenggara Jasa Internet Indonesia (APJII) menyebutkan bahwa pada periode tahun 2019 - kuartal II tahun 2020 jumlah pengguna internet di Indonesia mencapai 196,71 juta jiwa. Atau setara dengan 78 persen dari keseluruhan jumlah penduduk Indonesia. Angka tersebut meningkat sebanyak 8,9 persen dari tahun 2018, yang berarti dalam rentang satu tahun terdapat 25 juta pengguna internet baru di Indonesia (APJII, 2021). Namun jumlah pengguna internet yang besar tersebut tidak berbanding lurus dengan 
keadaban warga negara Indonesia dalam memanfaatkan internet. Pernyataan tersebut diperkuat dengan laporan hasil studi tahunan yang dilakukan oleh Microsoft yaitu Civil, Safety, and Interactions Online 2020. Untuk lebih detilnya dapat dilihat pada gambar di bawah ini.
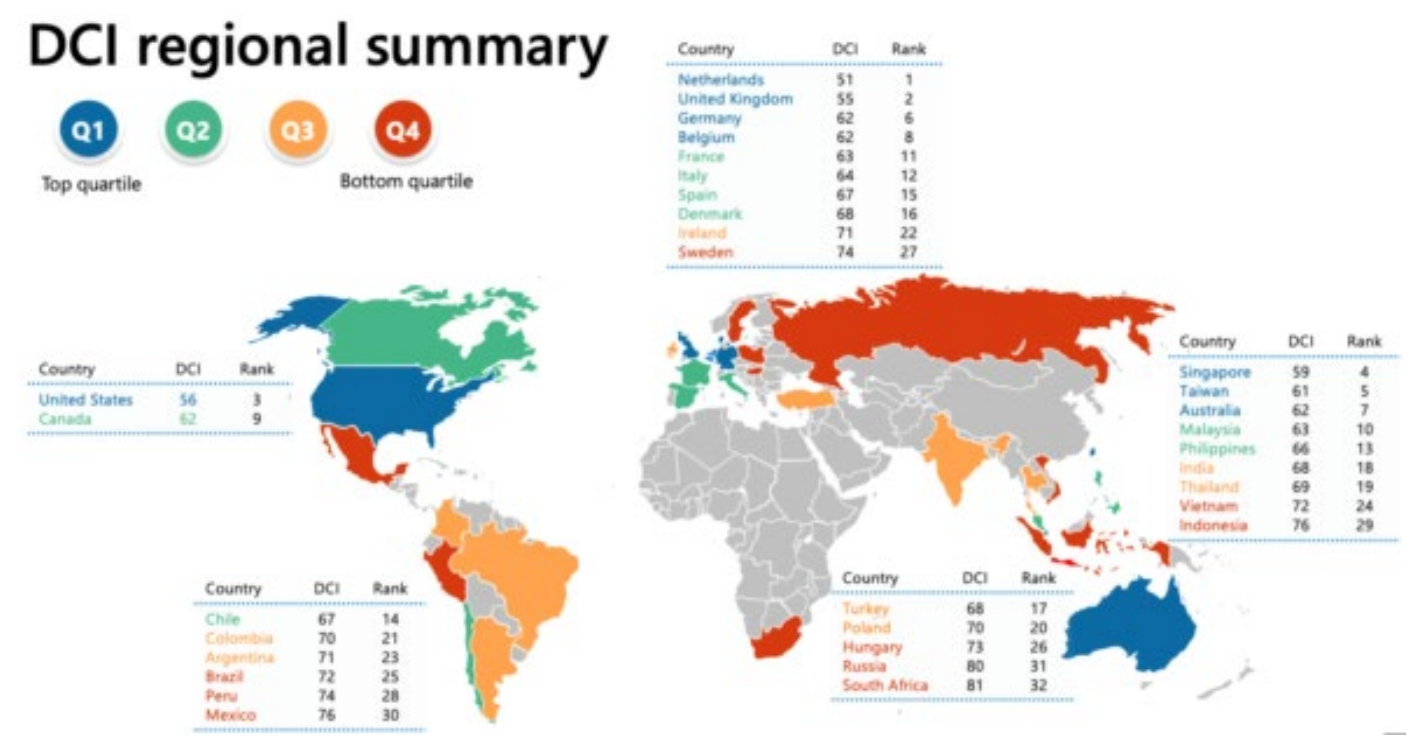

\author{
Gambar 1 \\ Ringkasan hasil DCI 2020 Microsoft
}

Sumber: Microsoft (2021)

Dalam laporan tersebut dimuat temuan dari Digital Civility Index (DCI) 2020, yang mengukur tingkat kesopanan digital dari pengguna internet dunia saat berkomunikasi di dunia maya. Secara total, ada lebih dari 16.000 responden dari 32 negara berpartisipasi dalam DCI 2020. Dari jumlah tersebut, 503 orang di antaranya berasal dari Indonesia. Penelitian ini dilakukan pada April dan Mei 2020. Dari survei tersebut, indeks keberadaban digital Indonesia berada pada posisi terburuk di Asia Tenggara (Digital Civility Index, 2021). Laporan tersebut secara umum menjelaskan bahwa netizen Indonesia kesopanan di media sosial lebih buruk dibandingkan tahun lalu. Status kesopanan pengguna Internet di Indonesia turun 8 poin menjadi 76 poin dalam satu tahun terakhir. Bagi pengguna Internet di Indonesia, risiko terbesar online adalah hoaks dan penipuan (scam), ujaran kebencian (hate speech), diskriminasi dan perundungan online (cyberbullying). Generasi millennial dan generasi $\mathrm{Z}$ menjadi kelompok yang paling sering mendapatkan perlakukan bully secara online.

Dari data tersebut, dapat disimpulkan bahwa keadaban warganet Indonesia masih rendah. Secara singkat literasi digital dapat diartikan sebagai keterampilan menggunakan media secara efektif sehingga individu dapat mengetahui tempat dan informasi yang relevan (Buckingham, 2010). Artinya, warganet Indonesia masih belum memiliki keterampilan dalam menggunakan media sosial secara efektif sehingga ia mampu mengetahui informasi dan menggunakannya untuk kepentingan yang berguna bagi dirinya dan masyarakat.

Pada kondisi warganet Indonesia yang seperti itu, Pemerintah Indonesia tetap berupaya untuk menghadapi perkembangan teknologi dengan mencanangkan "Making Indonesia 4.0". Yang berarti Pemerintah Indonesia berkomitmen untuk merevitalisasi setiap 19egati manufaktur nasional untuk ditopang dengan teknologi seperti Internet of Things (Io T) dan Artificial Intelligence (AI), Human Machine Interface, teknologi robotik dan sensor (Kementerian Perindustrian, 2018). Sektor pendidikan juga menjadi salah satu bidang yang didukung dengan teknologi.

Pendidikan juga harus berkembang sesuai dengan tuntutan zaman. Hal tersebut berarti bahwa pendidikan haruslah menjadi tempat bagi manusia untuk mempersiapkan dirinya agar menguasai ilmu pengetahuan, kemampuan, dan keahliannya lainnya agar mampu digunakan untuk kepentingan dirinya di masa yang akan datang. Pada konteks dunia digital ini, pendidikan mempunyai peran 
penting untuk dalam upaya pengembangan tersebut. Salah satunya adalah upaya mengedukasi masyarakat agar mampu menggunakan dan memanfaatkan teknologi untuk kepentingan peradaban manusia. Tujuan pendidikan yang seperti itu selaras dengan tujuan Pendidikan Kewarganegaraan yaitu "untuk membentuk warga negara yang baik (to be good citizen)" (Wahab \& Sapriya, 2011), juga mampu bertanggung jawab atas peran/tugasnya di dalam masyarakat, melindungi lingkungan, dan melindung hak asasi manusia (Budimansyah, 2010). Guna meningkatkan kemampuan literasi digital warga negara tersebut, maka Pendidikan Kewarganegaraan dapat diarahkan pada kualitas warganegara seperti yang diutarakan oleh Lee (1999) yaitu memiliki spiritual development, sense of individual responsibility, and reflective and autonomous personality (Winataputra \& Budimansyah, 2007) dan seperti konsep yang Cheng (1999) utarakan terkait PKn yang berorientasi pada konsep "contextualized multiple intelligence" dalam nuansa lokal, nasional, dan global (Winataputra \& Budimansyah, 2007). Sehingga warga negara itu diharapkan mampu memiliki pengembangan spiritual, manusia mandiri, memiliki intelegensi secara kontekstual sehingga ia mampu menggunakan teknologi dan informasi secara bertanggungjawab dan berguna untuk lingkungan sekitarnya.

Adapun komponen digital citizenship yang berkaitan dengan tujuan PPKn tersebut dan membantu kita untuk memberikan pandangan yang lebih luas terkait kemampuan atau kompetensi yang dibutuhkan dalam dunia digital, yaitu 1) digital etiquette; 2) digital access; 3) digital law; 4) digital communication; 5) digital literacy; 6) digital commerce; 7) digital rights and responsibility; 8) digital safety and security; and 9) digital health and wellness (Ribble et al., 2004). Namun implementasi pembelajaran PPKn yang berbasis teknologi belum terimplementasikan dengan baik di sekolah-sekolah. Salah satu yang menjadi hambatannya adalah fasilitas sekolah yang tidak mendukung teknologi dan informasi, kompetensi guru yang kurang dalam hal teknologi sehingga berpengaruh terhadap pemanfaatan pembelajaran yang berbasis teknologi (Sejati, 2011). Hal tersebut juga dapat diartikan bahwa siswa secara langsung tidak mengalami pembelajaran yang ditunjang dengan teknologi, sehingga tak jarang siswa yang kesulitan dalam memahami teknologi dan menggunakan teknologi dengan bijak.

\section{Metode}

Artikel ini disusun menggunakan pendekatan kualitatif dengan metode studi kepustakaan. Studi kepustakaan adalah metode penelitian yang bertujuan untuk mengkaji, meninjau, menganalisa ide-ide atau gagasan yang ada di dalam tubuh literatur yang berorientasi akademis. Teknik pengumpulan data yaitu dengan mengumpulkan sumber-sumber literatur terkait tema penelitian. Sedangkan analisis yang digunakan yaitu analisis isi.

\section{Hasil dan Pembahasan}

Pendidikan Kewarganegaraan yang telah lama berada di kurikulum pendidikan Indonesia dan PKn memiliki misi yang mulia yaitu membentuk warga negara yang baik dan cerdas sehingga terwujud partisipasi dan tanggungjawab dalam kehidupan berbangsa dan bernegara. Pendidikan Kewarganegaraan merupakan mata pelajaran yang memfokuskan pada pembentukan diri yang beragam dari segi agama, sosio kultural, bahasa, usia, dan suku bangsa menjadi warga negara Indonesia yang cerdas, terampil, dan berkarakter yang diamanatkan oleh Pancasila dan UUD NRI tahun 1945.

Cogan memberikan definisi tentang citizenship education yang terdiri dari kata a citizen, citizenship dan citizenship education, yaitu: A citizen was defined a constituent member of society. Citizenship on the other hand, was said to be 'a set of characteristics of being a citizen'. And finally, citizenship education, the underlying focal point of study, was defined as 'the contribution of education to development of those characteristics of being a citizen' (Cogan \& Kubow, 1997). Jadi menurut Cogan dan Kubow bahwa makna dari kata "a citizen" merujuk kepada anggota resmi suatu kelompok atau masyarakat, kemudian "citizenship" diartikan sebagai seperangkat karakteristik sebagai seorang warga negara dan "citizenship education" adalah kontribusi atau dampak pendidikan terhadap pengembangan karakteristik yang menandai seorang warga negara.

Sedangkan kriteria untuk menjadi warga negara yang baik dan ideal di era digital dan Abad 21 ini, Cogan dan Derricott mengajukan karakteristik sebagai berikut: 1) kemampuan untuk melihat 
dan mendekati masalah sebagai anggota masyarakat global; 2) kemampuan bekerja sama dengan yang lain dengan cara yang koperatif; 3) kemampuan memahami, menerima, menghargai, dan dapat menerima perbedaan-perbedaan budaya; 4) kapasitas berfikir dengan cara kritis dan sistematis; 5) keinginan untuk menyelesaikan konflik dengan cara tanpa kekerasan; 6) keinginan untuk mengubah gaya hidup dan kebiasaan konsumtif; 7) kemampuan bersikap sensitif dan melindungi hak asasi manusia (HAM); dan 8) keinginan dan kemampuan untuk ikut serta dalam politik (Cogan \& Derricott, 1998).

Perkembangan teknologi dan informasi di Abad 21 ini sangat cepat sehingga memengaruhi kehidupan manusia. Dunia mulai bergeser pada digitalisasi aspek-aspek kehidupan masyarakatnya dan pendidikan perlu beradaptasi sebagai usaha untuk mengajarkan kompetensi dalam menghadapi zaman tersebut. United Nation Convention on The Rights of The Child (UNCRC) Pasal 29 c, d yang menyatakan bahwa the preparation of the child for responsible life in a free society, in the spirit of understanding, peace, tolerance, equality of sexes, and friendship among all peoples, ethnic, national and religious groups and persons of indigenous origin (UNCRC, 1989). Yang berarti bahwa pendidikan perlu menumbuhkan karakter, bakat, kondisi mental, dan kemampuan fisik anak dan mengajarkan mereka pemahaman, perdamaian, dan kesetaraan gender dan persahabatan antarmanusia, dengan tetap menghormati budaya sendiri dan orang lain. Pendidikan perlu menyiapkan anak menjadi warga aktif di masyarakat bebas. Bagaimanapun juga, pernyataan tersebut juga sesuai dengan kewarganegaraan saat ini yang berkembang menjadi kewarganegaraan yang bersifat global (global citizenship) yang dapat dipahami sebagai konstruksi multidimensi yang bergantung pada saling keterkaitan antar dimensi tangjung jawab sosial, kompetensi global hingga keterlibatan warga negara secara global (Morais \& Ogden, 2011). Lebih penting lagi yaitu: more important are the activities that people not only understand in theory but was able to participate on the grounds that they understand the concept and what it does impact on them (Susanto \& Saylendra, 2018). Yaitu untuk membentuk warga negara yang baik diperlukan warganegara yang tidak hanya paham teori tetapi juga mampu melaksanakan teori tersebut.

Maka, untuk menghadapi setiap tantangan di era digital tersebut perlu adanya konsepsi ulang Pendidikan Kewarganegaraan di abad 21 agar mampu secra efektif mendidik peserta didik untuk menjadi warga negara yang memiliki fungsi. Oleh karena itu, pada abad 21 terminologi Pendidikan Kewarganegaraan harus dimaknai dalam konsep yang luas untuk menghadapi tantangan global (Banks, 2008). Senada dengan misi PKn berikut ini, yaitu Pendidikan Kewarganegaraan (Civic Education) adalah program pembelajaran yang, secara programatik prosedural berupaya memanusiakan (humanizing), membudayakan (civilizing), serta memberdayakan (empowering) manusia/anak didik untuk diri dan kehidupannya menjadi warga negara yang baik sebagaimana tuntutan keharusan yuridis konstitusional bangsa (Djahiri, 2006). Pendidikan kewarganegaraan digital bertujuan untuk mengembangkan kemampuan remaja yang terlibat secara aktif dalam komunitas komunikasi online mereka, agar dapat mengkonsumsi informasi online secara kritis, dan bertanggungjawab dengan melibatkan mereka secara aktif dalaam diskusi sosial dan politik secar online yang lebih positif (Mardianto, 2018).

Untuk memahami apa itu digital citizenship, kita perlu memulainya dari konsep kewarganegaraan (citizenship) itu sendiri. That is, "the state of being citizen of a particular social, political or national community (which) carries both rights and responsibilities (Alberta Education, 2012). Jadi, kewarganegaraan dalam pengertian tradisional dikaitkan dengan ruang terbatas dan atau kelompok individu, yang membutuhkan baik hak maupun tanggung jawab.

Kewarganegaraan digital (digital citizenship) meminta kita untuk mempertimbangkan bagaimana kita bertindak sebagai anggota dalam sebuah komunitas orang yang mencakup tetangga kita atau individu di negara belahan dunia dan hal tersebut membuat kita sadar bahwa teknologi menjembatani partisipasi kita dalam jaringan ini. Seperti pernyataan berikut, digital citizenship didesfinisikan sebagai "the norms of appropriate and responsible online behaviour" (Ribble et al., 2004) atau sebagai "the quality of habits, actions, and consumption patterns that impact the ecology of digital content and 
communities" (Heick, 2018). Jadi, setidaknya digital citizenship dapat diartikan sebagai norma yang pantas dan bertanggungjawab dalam interaksi dalam jaringan atau sikap dan kebiasaan yang berdampak pada konten digital dan komunitas yang baik. Dalam konteks persekolahan, pendidikan kewarganaegaraan digital dapat dipadupadankan dengan pendidikan karakter yang terintegrasi dengan Pancasila dan Kewarganegaraan mampu mengembangkan karakter guna menghadapi revolusi industri 4.0 (Susanto et al., 2020). Berbagai upaya yang dilakukan ini bertujuan untuk membentukan karakter melalui pembiasaaan. Pembiasaan atau habituasi dapat dilakukan di sekolah dalam upaya mengembangkan karakter dan watak kewarganegaraan (Susanto \& Komalasari, 2015). Sehinggan PKn

Berikut ini adalah element digital citizenship yang dikemukakan oleh Ribble: 1) digital etiquette; 2) digital access; 3) digital law; 4) digital communication; 5) digital literacy; 6) digital commerce; 7) digital rights and responsibility; 8) digital safety and security; and 9) digital health and wellness. Kesembilan elemen tersebut memberikan kita kemudahan dalam memahami kerangka dari digital citizenship itu sendiri. Elemen tersebut telah digunakan di negara seperti Kanada sebagai pondasi utama dalam membuat kebijakan tentang digital citizenship education pada tingkat dasar sampai tingkat atas. Untuk lebih jelasnya bagaimana pembagian element tersebut dapat dilihat pada bagan di bawah ini.

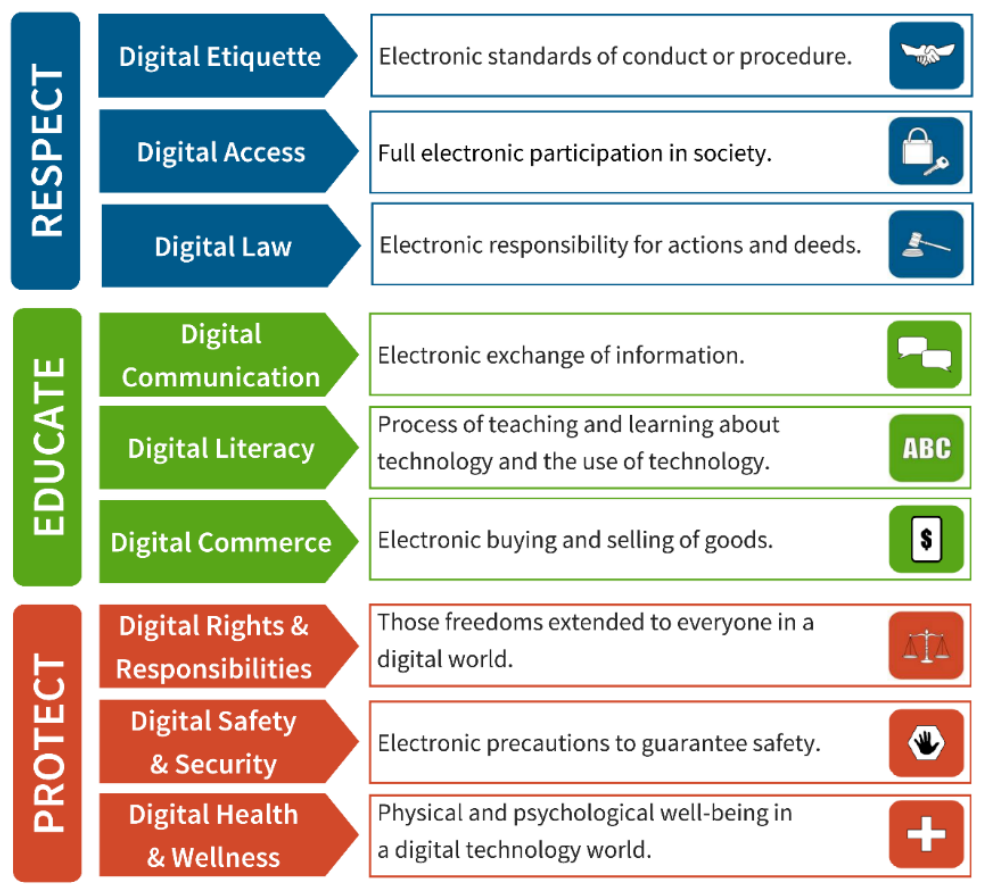

Gambar 2

Sembilan elemen digital citizenship Ribble

\section{Simpulan}

Berdasarkan hasil pemaparan di atas, dapat ditarik sebuah kesimpulan bahwa mendidik warganegara agar mampu bersaing di dunia digital diperlukan sistem pendidikan yang memfasilitasi peserta didik untuk mengembangkan kompetensi di era digital ini guna membangun keadaban digital warganet Indonesia saat ini dan masa yang akan datang. Dalam kewarganegaraan digital, tiga hal pokok yang menjadi tujuan adalah menghormati sesama pengguna internet, mendidik dan melindungi peserta didik dari hal negatif yang ditimbulkan oleh penggunaan internet dan dunia digital. Sekolah-sekolah di Indonesia sudah seharusnya memulai untuk menjalankan pendidikan kewarganegaraan digital untuk menjawab tantangan-tantangan dunia digital, salah satunya adalah bagaimana warga negara dapat berinteraksi baik online maupun offline secara sehat, baik, dan berakar empati dalam setiap kesempatan. 


\section{Ucapan Terima Kasih}

Lembaga Pengelola Dana Pendidikan (LPDP) yang telah memberikan dukungan kepada penulis. Serta Universitas Buana Perjuangan Karawang yang memberikan kesempatan kepada penulis untuk melanjutkan studi

\section{Referensi}

Alberta Education. (2012). Digital Citizenship Policy Development Guide. Alberta Ministry of Education.

APJII. (2021). Penambahan IIX dan Reduksi Belanja Trafik Internasional. Asosiasi Penyelenggara Jasa Internet Indonesia. https://apjii.or.id/content/read/104/531/BULETIN-APJII-EDISI-85--April-2021

Banks, J. A. (2008). Diversity, Group Identity, and Citizenship Education in a Global Age. Educational Researcher, 37(3), 129-139.

Buckingham, D. (2010). Defining Digital Literacy: What do young people need to know about digital media? Medienbildung in Neuen Kulturräumen, 1, 59-71. https://doi.org/10.1007/978-3-53192133-4_4

Budimansyah, D. (2010). Penguatan pendidikan kewarganegaraan untuk membangun karakter bangsa. Widya Aksara Press.

Cogan, J. J., \& Derricott, R. (1998). Citizenship for the 21 st Century: An International Perspective on Education. Kogan Page Limited.

Cogan, J. J., \& Kubow, P. K. (1997). Multidimentional citizenship: Educational policy for the twentyfirst century. International Service Learning \& Community Engagement, 2, 1-57.

Digital Civility Index. (2021). Civility, Safety, and Interactions Online.

Djahiri, K. (2006). Esensi Pendidikan Nilai Moral dan PKn di Era Globalisasi", dalam Pendidikan Nilai Moral dalam Dimensi Pendidikan Kewarganegaraan. Lab. PKn FPIPS UPI.

Heick, T. (2018). The Definition Of Digital Citizenship. https://www.teachthought.com/the-future-oflearning/the-definition-of-digital-citzenship/

Kementerian Perindustrian. (2018). Making Indonesia 4.0: Strategi RI Masuki Revolusi Industri Ke-4.

Mardianto. (2018). Peran Pendidikan Digital Citizenship Untuk Pencegahan Perilaku Ujaran Kebencian Siswa di Media Sosial. Membangun Manusia Indonesia Yang Holistik Dalam Kebhinekaan, 523-538.

Morais, D. B., \& Ogden, A. C. (2011). Initial Development and Validation of The Global Citizenship Scale,. Journal of Studies in International Education, 15(5), 445-446.

Ribble, M., Bailey, G., \& Ross, T. (2004). Digital Citizenship: Addressing Appropriate Technology Behavior. Learning \& Leading with Technology, 32(1), 6.

Sejati, N. D. R. I. (2011). Pemanfaatan Media Pembelajaran Pendidikan Kewarganegaraan Berbasis Teknologi Informasi dan Komunikasi (TIK) pada SMP Negeri 5 Semarang. 1-110.

Susanto, E., \& Komalasari, K. (2015). Pengaruh Pembelajaran, Habituasi Dan Ekstrakurikuler Terhadap Pembentukan Civic Disposition Siswa Sma Negeri Se-Kota Bandar Lampung. Jurnal Mimbar Demokrasi, 15(1).

Susanto, E., Putri, N., Sanusi, A. R., \& Sofyan, F. S. (2020). Pancasila and Civic Education as Reinforcement of the National's Character of High School Students in Karawang Regency to Face the Revolution Industry 4.0. 418(Acec 2019), 503-506. https://doi.org/10.2991/assehr.k.200320.095

Susanto, E., \& Saylendra, N. P. (2018). Civic Education as Empowerment of Civic Activism. Proceedings of the Annual Civic Education Conference (ACEC 2018). https://doi.org/10.2991/acec18.2018.4

Wahab, A. A., \& Sapriya. (2011). Teori dan landasan pendidikan kewarganegaraan. Alfabeta. 
Erwin Susanto, Dasim Budimansyah. Membangun keadaban digital warganet Indonesia dalam perspektif kewarganegaraan digital

Winataputra, U. S., \& Budimansyah, D. (2007). Civic Education $\square:$ Konteks, Landasan, Bahan Ajar dan Kultur Kelas (1st ed.). Program Studi Pendidikan Kewarganegaraan, Sekolah Pascasarjana UPI 